\title{
Atypical Flowers Can Be as Profitable as Typical Hummingbird Flowers
}

\author{
Nickolas M. Waser, ${ }^{1,2,}$ Paul J. CaraDonna, ${ }^{1,3}$ and Mary V. Price ${ }^{1,2}$ \\ 1. Rocky Mountain Biological Laboratory, Crested Butte, Colorado 81224; 2. School of Natural Resources and the Environment, \\ University of Arizona, Tucson, Arizona 85719; 3. Chicago Botanic Garden, Glencoe, Illinois 60022 \\ Submitted December 22, 2017; Accepted June 7, 2018; Electronically published September 12, 2018 \\ Dryad data: http://dx.doi.org/10.5061/dryad.cd4h7f1.
}

\begin{abstract}
Aвstract: In western North America, hummingbirds can be observed systematically visiting flowers that lack the typical reddish color, tubular morphology, and dilute nectar of "hummingbird flowers." Curious about this behavior, we asked whether these atypical flowers are energetically profitable for hummingbirds. Our field measurements of nectar content and hummingbird foraging speeds, taken over four decades at multiple localities, show that atypical flowers can be as profitable as typical ones and suggest that the profit can support 24-h metabolic requirements of the birds. Thus, atypical flowers may contribute to successful migration of hummingbirds, enhance their population densities, and allow them to occupy areas seemingly depauperate in suitable resources. These results illustrate what can be gained by attending to the unexpected.
\end{abstract}

Keywords: floral phenotype, foraging behavior, hummingbird energy budgets, hummingbird time budgets, nectar quantity, western North America.

You can observe a lot just by watching. (Yogi Berra)

It is important not to confuse the description with that which is described. (Max Tegmark 2014, p. 265)

\section{Introduction}

Hummingbirds are quintessential avian pollinators whose extraordinary metabolic requirements are fueled primarily by flower nectar (Scheithauer 1967; Powers and Nagy 1988; Brice 1992). The bills and tongues of these charismatic animals are superbly adapted to extract nectar (Rico-Guevara et al. 2015), including the concentrated nectar they prefer (Roberts 1996). They metabolize nectar sugar rapidly and efficiently (Karasov et al. 1986). Agile hovering flight (Dakin et al. 2018) gives

\footnotetext{
* Corresponding author; email: nickolas.waser@ucr.edu. ORCIDs: Waser, http://orcid.org/0000-0001-8416-5037.
}

Am. Nat. 2018. Vol. 192, pp. 644-653. (C) 2018 by The University of Chicago. 0003-0147/2018/19205-58156\$15.00. All rights reserved. DOI: $10.1086 / 699836$ them an exceptional ability to approach and handle flowers without landing. They possess acute color vision and lack innate preference for colors ranging from near UV to long red wavelengths (Stiles 1976; Goldsmith and Goldsmith 1979; Lunau et al. 2011). They also possess a sense of smell (Goldsmith and Goldsmith 1982; Knudsen et al. 2004). The ability to distinguish diverse floral sensory signals and to utilize a range of nectar resources and floral morphologies suggests that many hummingbird species will be generalized in their use of flowers, and natural history records confirm this (e.g., Bent 1940; Bené 1946; Grant and Grant 1968; Austin 1975; Johnsgard 1983; Waser 1983; Calder 2004).

At the same time, a common perception is that hummingbirds mostly associate with typical "hummingbird flowers"a strikingly convergent set of flowers that often are reddish and unscented, with dilute nectar produced at the base of elongated tubular corollas or spurs (e.g., fig. $1 A-1 D$; Grant and Grant 1968; Skutch and Singer 1973; Grant and Temeles 1992; Lunau et al. 2011). This perception is understandable. Hummingbird visits to flowers are visually striking, and it is natural to focus on those involving bright colors (such as red and orange) that humans see well. Furthermore, the shared features of distantly related flowers, such as tubular shape, make sense as convergent adaptations to exploit hummingbird morphology and behavior in the interest of pollen transfer.

But the literature and observation in the field also show that hummingbirds visit flowers that are not red, tubular, or scentless and that produce concentrated nectar (fig. 1E$1 K)$. This raises new questions: Are visits to "atypical" flowers just chance encounters or mistakes, or are they important for hummingbird energetics? Past studies show that insects and other animals that rely on nectar, including hummingbirds, are sensitive to the economics of foraging (e.g., Pyke 1984). Perhaps, then, many hummingbirds will readily accept atypical flowers when these are energetically profitable.

In what follows, we bring together records of hummingbird visits to typical and atypical flowers gleaned from our field notes taken over four decades in southwestern North America. 

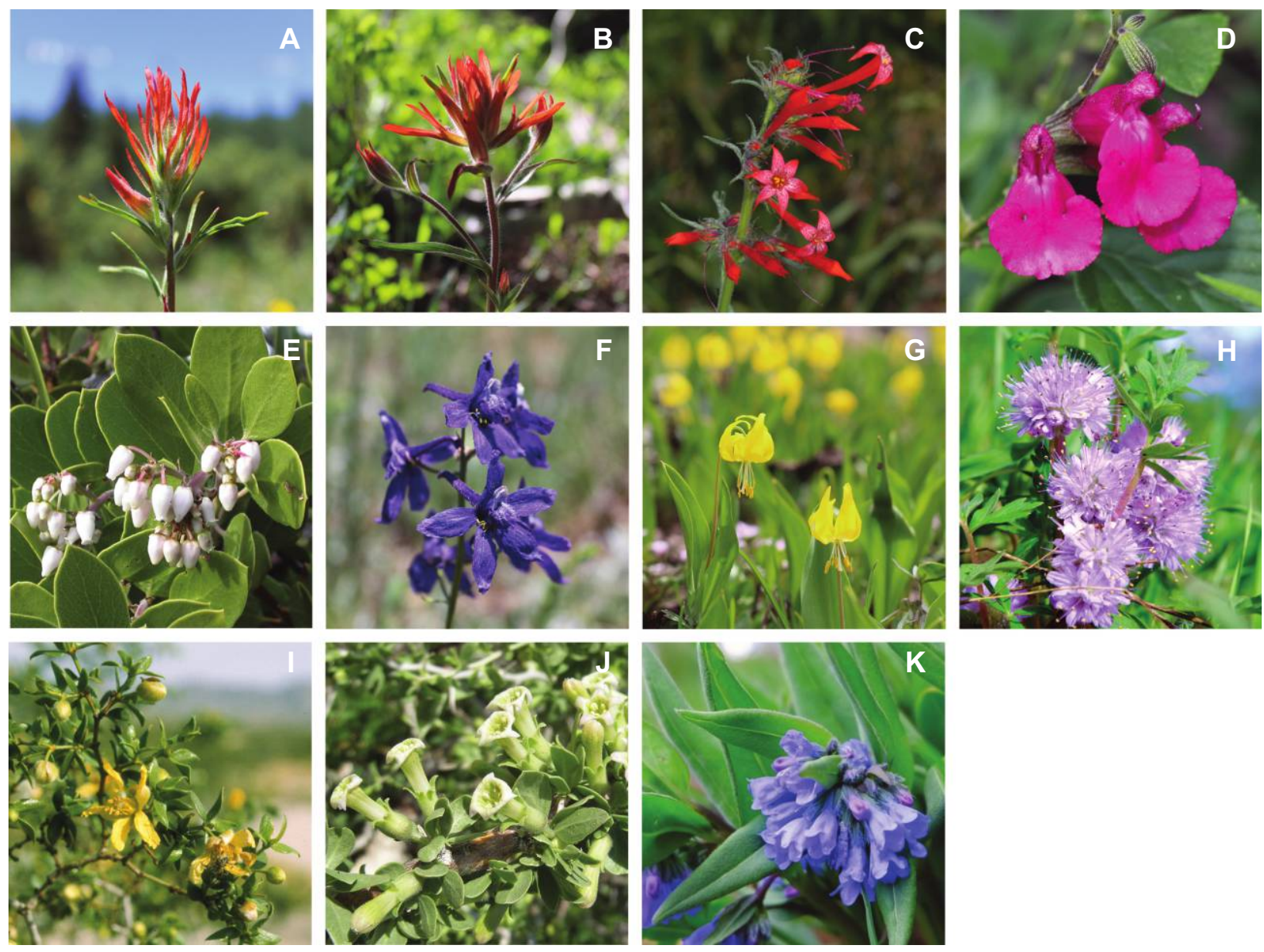

Figure 1: Flower species included in this study. $A-D$, Typical hummingbird flowers: Wyoming paintbrush (Castilleja linariifolia; $A$ ), giant red paintbrush (Castilleja miniata; $B$ ), scarlet gilia (Ipomopsis aggregata; $C$ ), Lemmon's sage (Salvia lemmonii; $D$ ). E-K, Atypical flowers visited by hummingbirds: point-leaf manzanita (Arctostaphylos pungens; E), Nuttall's larkspur (Delphinium nuttallianum; F), glacier lily (Erythronium grandiflorum; $G$ ), ballhead waterleaf (Hydrophyllum capitatum; $H$ ), creosote bush (Larrea tridentata; $I$ ), peach thorn (Lycium cooperi; J), sagebrush bluebell (Mertensia oblongifolia; $K$ ). Photo credits: $A, B, F, G$, Paul CaraDonna; $C$, David Inouye; $D$, Bart Jones; $E$, Keir Morse; H, K, Jane Ogilvie; I, Gary Monroe; J, Neal Kramer.

These records allow us to estimate how much energy hummingbirds gain from the flowers, and published studies provide estimates of how much energy they expend. Calculations show that atypical flowers can yield energetic profits as rich as those from typical flowers - profits that, if maintained, would support resident hummingbirds. We contemplate what this may mean for hummingbird populations and their conservation, whether atypical flowers might benefit from hummingbird visits, and what our study illustrates more generally about the value of attending to natural history.

\section{Methods}

\section{Basic Approach}

We can estimate the rate at which a hummingbird acquires energy while foraging from simultaneous field measurements of the volume of nectar per flower, the sugar content of the nectar, and the foraging rate of the bird. Published physiological studies provide estimates of the mass-specific rate at which hummingbirds expend energy during different activities. By combining this with information on body mass, day length, and ambient temperature, we can estimate whole-animal metabolic cost for a 24-h cycle. This cost can then be compared with estimated energy gain from flower nectar.

We first describe these energy budget calculations and illustrate their application with hummingbirds visiting pointleaf manzanita (Arctostaphylous pungens). We then summarize calculations for three additional atypical flowers and three typical hummingbird flowers at which we have observed systematic foraging (table 1). Data underlying table 1 are deposited in the Dryad Digital Repository: http://dx.doi.org/10 .5061/dryad.cd4h7f1 (Waser et al. 2018). Finally, we compare 
Table 1: Estimated per-flower nectar reward and (where available) hummingbird foraging rates and gross energy gain, from field samples of atypical and typical species

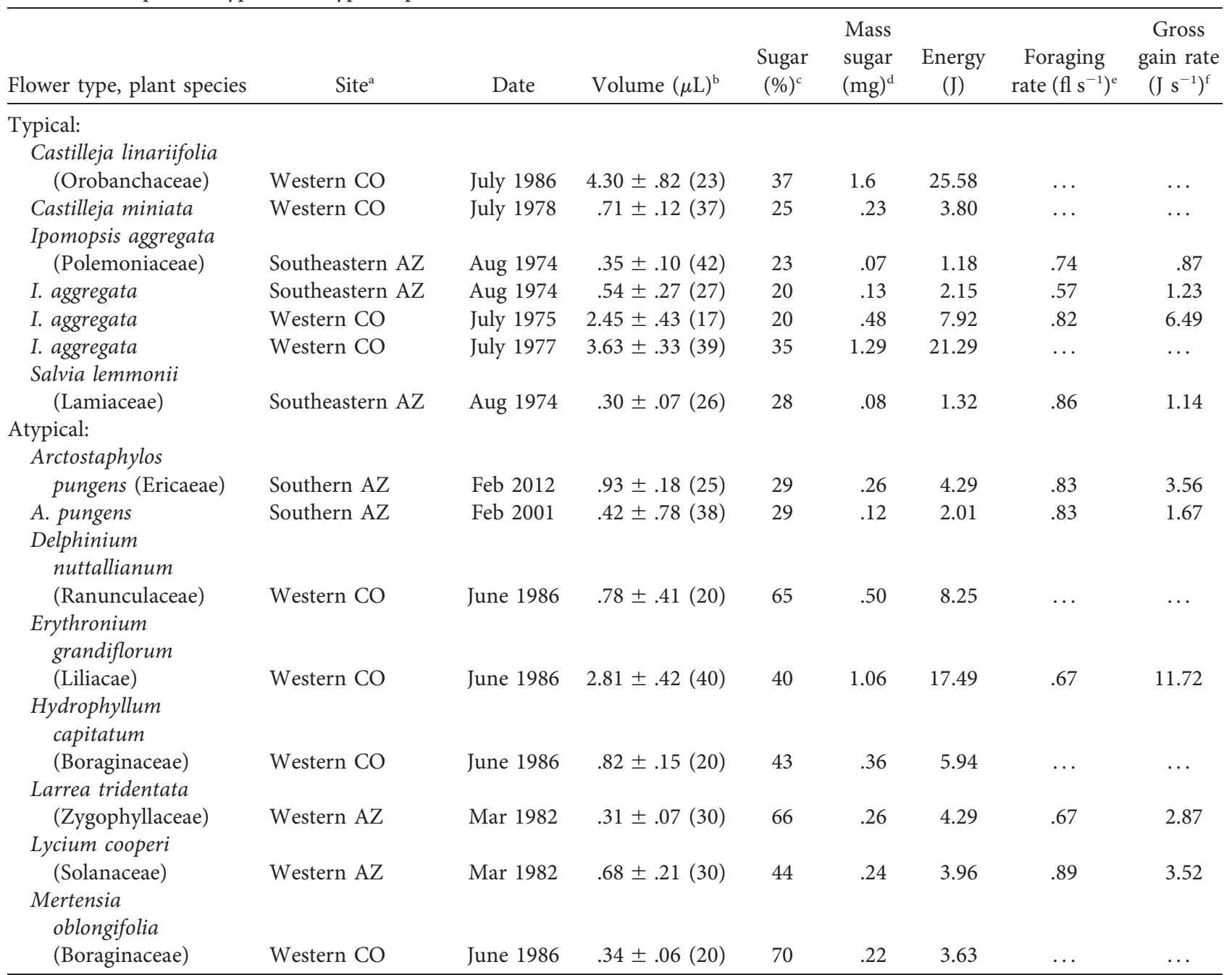

a Site descriptions. Western Colorado: Rocky Mountain Biological Laboratory (RMBL); $2,900 \mathrm{~m}$ elevation, $38.97^{\circ} \mathrm{N}, 106.98^{\circ} \mathrm{W}$. Extensive mostly dry subalpine meadows dominated by $\sim 60$ species of native perennial wildflowers, interspersed with forest of aspen (Populus tremuloides), Engelmann spruce (Picea engelmannii), and subalpine fir (Abies lasiocarpa). Nectar standing volumes for glacier lilies measured June 5, 1986, from 0900 to 1000 hours; for Wyoming paintbrush, July 28, 1986, from 1200 to 1500 hours; for giant red paintbrush, July 7, 1978, from 1000 to 1200 hours; for scarlet gilia, July 8, 1975 , from 1300 to 1400 hours and July 9, 1977, from 1000 to 1100 hours; for sagebrush bluebell and ballhead waterleaf, June 5, 1986, from 1000 to 1100 hours; and for Nuttall's larkspur, June 5, 1986, from 1100 to 1200 hours. Southeastern Arizona: Turkey Flat, Pinaleño Mountains; $2,260 \mathrm{~m}$ elevation, $32.63^{\circ} \mathrm{N}, 109.82^{\circ} \mathrm{W}$. Open xeric ponderosa pine (Pinus ponderosa) woodland with a sparse understory of native herbaceous wildflowers and shrubs. Nectar standing volumes for scarlet gilia measured on August 18 , 1974, in early afternoon and on August 28, 1974, from 1100 to 1200 hours (patches defended by, respectively, male and female Broad-tailed Hummingbirds) and for Lemmon's sage on August 18, 1974, from 1100 to 1200 hours. Southern Arizona: Gordon Hirabayashi Recreation Site, Santa Catalina Mountains north of Tucson; $1,500 \mathrm{~m}$ elevation, $32.34^{\circ} \mathrm{N}, 110.78^{\circ} \mathrm{W}$. Upper Sonoran grassland interspersed with abundant manzanita bushes (Arctostaphylos pungens) along with oaks (Quercus spp.) in more mesic washes. Nectar standing volumes for manzanita measured February 15, 2012, from 1300 to 1500 hours. Western Arizona: Large desert wash bisected by Hovatter Road, $\sim 60 \mathrm{~km}$ east of the town of Quartzsite; $400 \mathrm{~m}$ elevation, $33.62^{\circ} \mathrm{N}, 113.62^{\circ} \mathrm{W}$. Mesic wash vegetation with common peachthorn (Lycium cooperi), wolfberry (L. andersonii; in fruit at the time of our study), brittlebush (Encelia farinosa), and paloverde (Parkinsonia florida); Lower Sonoran desert scrub outside the wash dominated by dense creosote bush (Larrea tridentata) and white bursage (Ambrosia dumosa) with occasional saguaro (Carnegiea gigantea) and ocotillo (Fouquieria splendens; in bud at the time of our study). Nectar standing volumes for peach-thorn and creosote bush measured March 20, 1982, from 0900 to 1000 hours.

${ }^{\mathrm{b}}$ Volume is expressed as mean $\pm 1 \mathrm{SE}$ (number of flowers). The second value for A. pungens is from Richardson and Bronstein (2012); concentration and foraging rate for this example are from our 2012 sample at the same site.

${ }^{\mathrm{c}}$ Sucrose-equivalent nectar concentration; mass of solute per volume of solution. Refractometer readings were not obtained from some flowers, and we sometimes combined nectar from flowers to obtain readings; hence, these values usually represent subsamples of flowers whose nectar volumes we measured, and SEs are not given.

${ }^{\mathrm{d}}$ Mean milligrams of sucrose-equivalent sugar per flower.

e Average flowers per second for the hummingbird species and sex observed foraging at these flowers.

${ }^{\mathrm{f}}$ Estimated gross rate of energy intake while foraging calculated from foraging rate and energy content. 
available nectar rewards in several additional atypical and typical flowers for which we lack information on foraging rates (table 1).

\section{Estimating What a Flower Provides}

We extracted nectar from flowers in the field, measured its volume with calibrated glass microcapillary tubes (Drummond Scientific, Broomall, PA), and measured its concentration with a hand refractometer. We converted refractometer readings of mass of solute per mass of solution to mass of solute per volume of solution (see Bolton et al. 1979). These volumetric concentrations can be multiplied by volume to estimate the mass of sugar in a sample. Floral nectar is dominated by sucrose and its component monosaccharides (e.g., Frey-Wyssling et al. 1954); these sugars in any combination yield equivalent energy content (Martínez del Rio et al. 1992) of $16.5 \mathrm{~J} \mathrm{mg}^{-1}$ sugar (Powers and Conley 1994).

We assume here that hummingbirds remove all available nectar from flowers and that all sugar is absorbed by the hummingbird gut (Karasov et al. 1986). The hummingbirds we observed have bill lengths of 17-19 mm (mean lengths of exposed culmen, from Johnsgard [1983] and our own measurements; table 2). Hummingbird tongues can reach nectar at a depth of about twice the bill length (e.g., Grant and Temeles 1992). All flowers we discuss either are open or have corolla tubes shallower than the shortest of the hummingbird bills plus extended tongues.

\section{Estimating What Hummingbirds Need}

Hummingbirds expend energy at different rates when flying, sitting on a perch, or sleeping (table 2). The most costly activity is hovering flight. Laboratory measurements show that hovering consumes about $41.5 \mathrm{~mL}$ oxygen $\mathrm{g}^{-1}$ body mass $\mathrm{h}^{-1}$, equivalent to $833 \mathrm{~J} \mathrm{~g}^{-1} \mathrm{~h}^{-1}$ if we assume that each milliliter of oxygen consumed yields 20.08 J of energy (Lasiewski 1963; Calder et al. 1990). For comparison, perching while alert and sleeping at normal body temperature consume about 11 and $6.5 \mathrm{~mL}$ oxygen $\mathrm{g}^{-1} \mathrm{~h}^{-1}$, respectively (Wolf and Hainsworth 1971; Wolf et al. 1972). Hummingbirds can also enter torpor at night, maintaining a body temperature slightly above ambient (e.g., Calder and Booser 1973). The energetic cost of torpor is far below that of sleep at normal body temperature (Lasiewski 1963).

Activity-specific metabolic costs and time budgets can be combined to estimate the total daily energy expenditure of a hummingbird:

$$
E_{24 \mathrm{~h}}=\sum_{i}\left(E_{i} \times t_{i}\right),
$$

where $E_{24 \mathrm{~h}}$ is total energy expenditure per day, $E_{i}$ is the energetic cost $\left(\mathrm{J} \mathrm{h}^{-1}\right)$ of activity $i$ (flying, perching, sleeping), and $t_{i}$ is the hours spent engaged in activity $i$ per $24 \mathrm{~h}$. Estimates derived in this way ignore varying costs of different flight behaviors and details of the thermal environment (Weathers et al. 1984), but they suffice to indicate whether a floral resource provides an energetic profit, especially since we make the conservative assumption that all flight is as costly as expensive hovering flight.

A hummingbird's daily energy gain can be estimated by multiplying the number of flowers visited per unit of time spent foraging, energy obtained per flower (as described above), and time spent foraging per day. We estimated foraging rates by counting numbers of flowers visited and by timing foraging bouts with mechanical Swiss stopwatches at the same times and in the same populations in which we measured nectar. We first assume that a hummingbird spends 15\% of daylight hours foraging for nectar, $3 \%$ in other activities that involve flight (such as courtship, aggression, or travel to a nest), and $82 \%$ perching (Wolf and Hainsworth 1971; this agrees with other time budgets from the western United States; e.g. Calder 1971; Waser 1976). We later relax this assumption.

\section{Results and Discussion}

\section{Hummingbird Foraging Energetics at Manzanita}

Point-leaf manzanita (fig. $1 E$ ) is a large shrub that produces hundreds to thousands of tiny bell-shaped, white-to-pink flowers about $6 \mathrm{~mm}$ long with an aperture of 1-2 mm (Richardson and Bronstein 2012) - hardly a typical hummingbird flower. In February 2012, we observed a male Anna's Hummingbird foraging systematically within a large population of manzanita in southern Arizona (dates and locations are given in the table 1 notes). No other plants were in flower at this location or nearby; manzanita represented the only available nectar resource at this time of year (N.M.W., P.J.C., and M.V.P., personal observations). A sample of flowers had a mean standing volume of nectar equivalent to $4.29 \mathrm{~J}$ per flower $\left(\mathrm{J} \mathrm{fl}^{-1}\right.$; table 1$)$.

If we assume the average body mass and activity-specific energetic costs of an Anna's Hummingbird (table 2), that it flew for $18 \%$ of the $11 \mathrm{~h}$ of daylight available (i.e., $1.98 \mathrm{~h}$ ), and that it maintained normal body temperature overnight, we can estimate the 24 -h metabolic cost using equation (1):

$$
\begin{aligned}
E_{24 \mathrm{~h}}= & \left(3,583 \mathrm{~J} \mathrm{~h}^{-1} \times 1.98 \mathrm{~h}\right)+\left(950 \mathrm{~J} \mathrm{~h}^{-1} \times 9.02 \mathrm{~h}\right) \\
& +\left(561 \mathrm{~J} \mathrm{~h}^{-1} \times 13 \mathrm{~h}\right) \\
= & 22,956 \mathrm{~J} .
\end{aligned}
$$

If the bird were to enter torpor overnight, the corresponding cost would be approximately 15,800 J (table 2), assuming slightly less than $0.1 \mathrm{~mL}$ oxygen $\mathrm{g}^{-1} \mathrm{~h}^{-1}\left(8 \mathrm{~J} \mathrm{~h}^{-1}\right.$; fig. 3 of Lasiewski 1963) at an overnight ambient temperature of $10^{\circ} \mathrm{C}$ (table 2 of Calder 1971). 
Table 2: Estimated metabolic costs for hummingbirds observed in this study

\begin{tabular}{|c|c|c|c|c|c|c|c|c|}
\hline \multirow[b]{3}{*}{ Hummingbird $^{a}$} & \multirow[b]{3}{*}{ Bill length (mm) } & \multirow[b]{3}{*}{ Mass (g) } & \multicolumn{6}{|c|}{ Energy $\cos ^{\mathrm{b}}$} \\
\hline & & & \multirow[b]{2}{*}{ Flying $\left(\mathrm{J} \mathrm{h}^{-1}\right)$} & \multirow[b]{2}{*}{ Perching $\left(\mathrm{J} \mathrm{h}^{-1}\right)$} & \multicolumn{2}{|c|}{ Sleeping $\left(\mathrm{J} \mathrm{h}^{-1}\right)^{\mathrm{c}}$} & \multicolumn{2}{|c|}{ Per $24 \mathrm{~h}(\mathrm{~J})^{\mathrm{d}}$} \\
\hline & & & & & Normal & Torpid & Normal & Torpid \\
\hline Anna’s (male) & 18.1 & 4.30 & 3,583 & 950 & 561 & 8 & 22,956 & 15,767 \\
\hline Costa’s (male) & 17.0 & 3.05 & 2,542 & 673 & 398 & 18 & 17,194 & 12,824 \\
\hline Broad-tailed (male) & 17.2 & 3.16 & 2,633 & 698 & 412 & 6 & 19,085 & 15,228 \\
\hline Broad-tailed (female) & 18.4 & 3.60 & 3,000 & 795 & 470 & 14 & 20,665 & 15,649 \\
\hline Rufous (male) & 18.0 & 3.22 & 2,683 & 711 & 420 & 12 & 18,477 & 13,989 \\
\hline
\end{tabular}

To estimate energy gain from manzanita, we assume 15\% of 11 daylight hours devoted to foraging (i.e., $1.65 \mathrm{~h}=5,940 \mathrm{~s}$ ), the observed foraging rate of $0.83 \mathrm{fl} \mathrm{s}^{-1}$, and $4.29 \mathrm{Jfl}^{-1}$ (table 1 ). This yields 4,930 flowers visited per day and a total daily energy gain of 21,150 J, slightly below the estimated expenditure without overnight torpor. This suggests that if a hummingbird could maintain the rate of intake we estimate, manzanita flowers at this time and place would suffice to support overnight residency, with some period of torpor.

\section{Hummingbird Foraging Energetics at Other Atypical Flowers}

Our field notes provide other examples of atypical flowers whose nectar might support resident hummingbirds. We first describe three of these for which we have information on hummingbird foraging rates (table 1).

In March 1982, we observed territorial male Costa's Hummingbirds systematically foraging from peach-thorn (Lycium cooperi; fig. $1 J$ ) in the desert of western Arizona (table 1). This native shrub produces hundreds of greenish-white flowers with short tubular corollas $\sim 10.5 \mathrm{~mm}$ long and $3.0 \mathrm{~mm}$ wide. Using equation (1), we conclude that a Costa's male could visit 6,143 flowers in $12.5 \mathrm{~h}$ of daylight and gain $24,326 \mathrm{~J}$ if it maintained the per-flower rewards and foraging rates in table 1 . This gross energy gain exceeds the 24 -h metabolic cost without overnight torpor (table 2).

Peach-thorn was not the only atypical flower visited at this site in March 1982. The abundant yellow, open, $\sim 1.5-\mathrm{cm}-$ wide flowers of creosote bush (Larrea tridentata; fig. 1I) provided a mean nectar reward of $4.29 \mathrm{~J}$ (table 1 ). A male Costa's Hummingbird foraging only at creosote bush could visit about 4,523 flowers per day, yielding 19,404 J, also sufficient for support without overnight torpor (table 2).
Finally, soon after snowmelt near the Rocky Mountain Biological Laboratory (RMBL) in western Colorado (table 1), Broad-tailed Hummingbirds of both sexes often visit the open, $\sim 5$-cm-wide yellow flowers of glacier lily (Erythronium grandiflorum; fig. $1 G$ ). Flowers averaged a reward of more than $10 \mathrm{~J}$ (table 1) in June 1986, and our estimated hummingbird visitation of 5,246 flowers in a 13.5-h day would have yielded $91,753 \mathrm{~J}$, far in excess of the 24 -h requirement (table 2 ; the requirement for a Colorado female is about 1.14 times that given for the Colorado male: 21,756 J without and 17,360 J with overnight torpor).

\section{Is a Hummingbird's Time Budget Fixed?}

The conditions under which resident hummingbirds can be supported by floral rewards are broader than the calculations so far imply. Consider again a 4.3-g male Anna's Hummingbird that expends $3,583 \mathrm{~J} \mathrm{~h}^{-1}$ while foraging, or about $1 \mathrm{~J} \mathrm{~s}^{-1}$. If the bird visits $0.83 \mathrm{fl} \mathrm{s}^{-1}$, as we assumed for manzanita, a per-flower profit will be realized as long as each flower's nectar contains more than $1.20 \mathrm{~J}$ on average. This is slightly more than one-quarter of the $0.26 \mathrm{mg}$ of sugar that we measured in 2012 for an average manzanita flower. The mean standing crop of nectar in flowers varies considerably, however. For example, Richardson and Bronstein (2012) obtained only $0.42 \mu \mathrm{L}$ of nectar per manzanita flower in a $2001 \mathrm{sam}-$ ple at the same study site we used, about $45 \%$ of our value of $0.93 \mu \mathrm{L}$ (table 1). Assuming the nectar concentration that we measured in 2012, each flower averaged about $2.01 \mathrm{~J}$. If a hummingbird adopts a time budget as before and visits 4,950 flowers during $1.65 \mathrm{~h}$ of foraging, it accumulates 9,950 J, far less than our estimated 24 -h requirement, even with torpor (table 2). This appears to validate the conclusion of Rich- 
ardson and Bronstein (2012): the Anna's Hummingbirds they observed at flowers were not supported by nectar.

However, even with the $2.01 \mathrm{~J} \mathrm{fl}^{-1}$ measured in 2001 (Richardson and Bronstein 2012), birds would still gain an average per-flower net profit of $2.01-1.20=0.81 \mathrm{~J}$. If a hummingbird were to increase the time allocated to foraging from $1.65 \mathrm{~h}$ ( $15 \%$ of 11 daylight hours) to $3.13 \mathrm{~h}(28 \%)$, it would accumulate an energetic profit sufficient to allow 24-h residency with nocturnal torpor. This "breakeven" foraging allocation (fig. 2) is calculated by setting total gross energy gain (time spent foraging multiplied by energy acquired per flower) equal to minimal 24-h metabolic cost (i.e., a cost assuming that the bird spends all day either perching or foraging).

Several observations suggest that hummingbirds will indeed extend foraging activity in anticipation of future energy needs. While characterizing the time budgets of male Broadtailed Hummingbirds at the RMBL, one of us (N.M.W.) observed that time spent foraging suddenly increased as nighttime approached. Field notes from 1975, for example, show that the focal hummingbird tripled its feeding rate between 1630 and 1930 hours compared with the previous eight day-

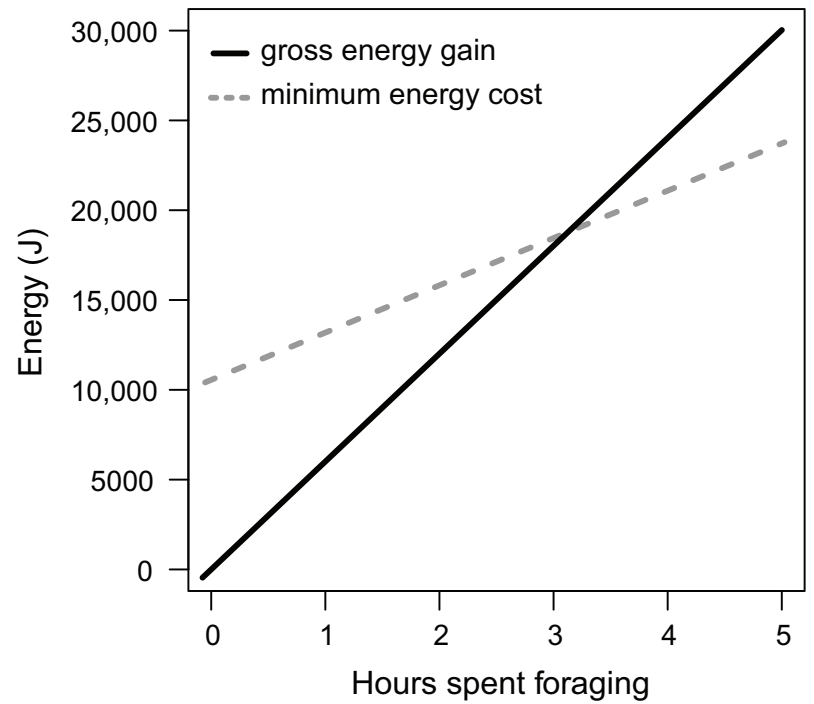

Figure 2: Graphical illustration of the "breakeven" time allocation to foraging that balances minimal 24-h metabolic costs for a 4.3-g male Anna's Hummingbird foraging at point-leaf manzanita (Arctostaphylos pungens) while obtaining $2.01 \mathrm{~J} \mathrm{fl}^{-1}$. If the bird visits at a rate of $0.83 \mathrm{fl} \mathrm{s}^{-1}$, its gross rate of energy gain is $6,006 \mathrm{~J} \mathrm{~h}^{-1}$ while foraging $\left(3,600 \mathrm{~s} \times 0.83 \mathrm{fl} \mathrm{s}^{-1} \times\right.$ $2.01 \mathrm{~J} \mathrm{fl}^{-1}$ ), and its total daily gain equals the gross rate of gain multiplied by time spent foraging (gross energy gain line). Its minimal metabolic cost with zero time foraging would be $11 \mathrm{~h}$ of daylight spent perching at $950 \mathrm{~J} \mathrm{~h}^{-1}$ and $13 \mathrm{~h}$ in nighttime torpor at $8 \mathrm{~J} \mathrm{~h}^{-1}$ (table 2), or 10,554 J for $24 \mathrm{~h}$. Each daylight hour spent foraging adds 3,583-950 = 2,633 J to this requirement (minimal energy cost line). The breakeven number of hours $(x)$ spent foraging is the time where the lines cross and gain equals cost. In this example, $x=10,554 /(6,006-2,633)=3.13 \mathrm{~h}$. light hours; he disappeared to roost for the night at 2012 hours Calder et al. (1990) determined that Broad-tailed Hummingbirds concentrate on feeding in the final period of daylight for long enough to accumulate the energy necessary to survive the night without torpor. Hummingbirds also change time budgets in response to available energy. By experimentally reducing flower availability, Hixon et al. (1983) caused an immediate increase in allocation to foraging by immature Rufous Hummingbirds (Selasphorus rufus); and by reducing sugar concentration at feeders, Powers (1987) caused freeflying Anna's Hummingbirds to abandon costly aggression and courtship activity.

Thus, hummingbird time budgets are flexible in anticipation of energy requirements and in response to energy availability. As a result, 24-h residency should be possible when days are long enough and floral resources are sufficient for birds to gain enough energy during daylight to offset nocturnal costs. If more time or energy is available, birds could add expensive behaviors, such as territorial aggression, courtship, or nesting - responses that are suggested by the studies of Calder and Booser (1973), Gass and Lertzman (1980), Powers (1987), and Powers and Conley (1994).

\section{Relative Value of Atypical and Typical Hummingbird Flowers}

Another question is how closely atypical flowers resemble typical hummingbird flowers in their energetic rewards. Some have argued (e.g., Heinrich and Raven 1972, p. 597) that floral nectar rewards evolve in response to the energy needs of pollinators. Under this hypothesis, flowers adapted primarily for hummingbird pollination are expected to offer substantially greater rewards than flowers adapted primarily for insects.

We can evaluate this idea by comparing estimates of energy gain for several observations of hummingbirds visiting typical hummingbird flowers with estimates for the atypical flowers discussed so far. In August 1974, in western Arizona (table 1), a male Rufous Hummingbird in a patch of Lemmon's sage (Salvia lemmonii; a magenta hummingbird flower; fig. $1 D$ ), averaged $0.86 \mathrm{fl} \mathrm{s}^{-1}$ and realized an estimated profit of $1.14 \mathrm{~J} \mathrm{~s}^{-1}$. Similarly, a female Broad-tailed Hummingbird at the same site visiting scarlet gilia (Ipomopsis aggregata; a red tubular hummingbird flower; fig. $1 C$ ) averaged $0.74 \mathrm{fl} \mathrm{s}^{-1}$ and realized an estimated profit of $0.87 \mathrm{~J} \mathrm{~s}^{-1}$. A male Broadtailed Hummingbird at the RMBL visiting I. aggregata in July 1975 averaged $0.82 \mathrm{fl} \mathrm{s}^{-1}$ and obtained an estimated profit of $1.23 \mathrm{~J} \mathrm{~s}^{-1}$. These profits (table 1; fig. 3) are actually somewhat below those estimated for the atypical flowers discussed above.

Certainly hummingbird flowers sometimes offer substantially more energy to visitors than these examples suggest, as is evident from samples from the RMBL of I. aggregata in 1977 and of Wyoming paintbrush (Castilleja linariifolia) 


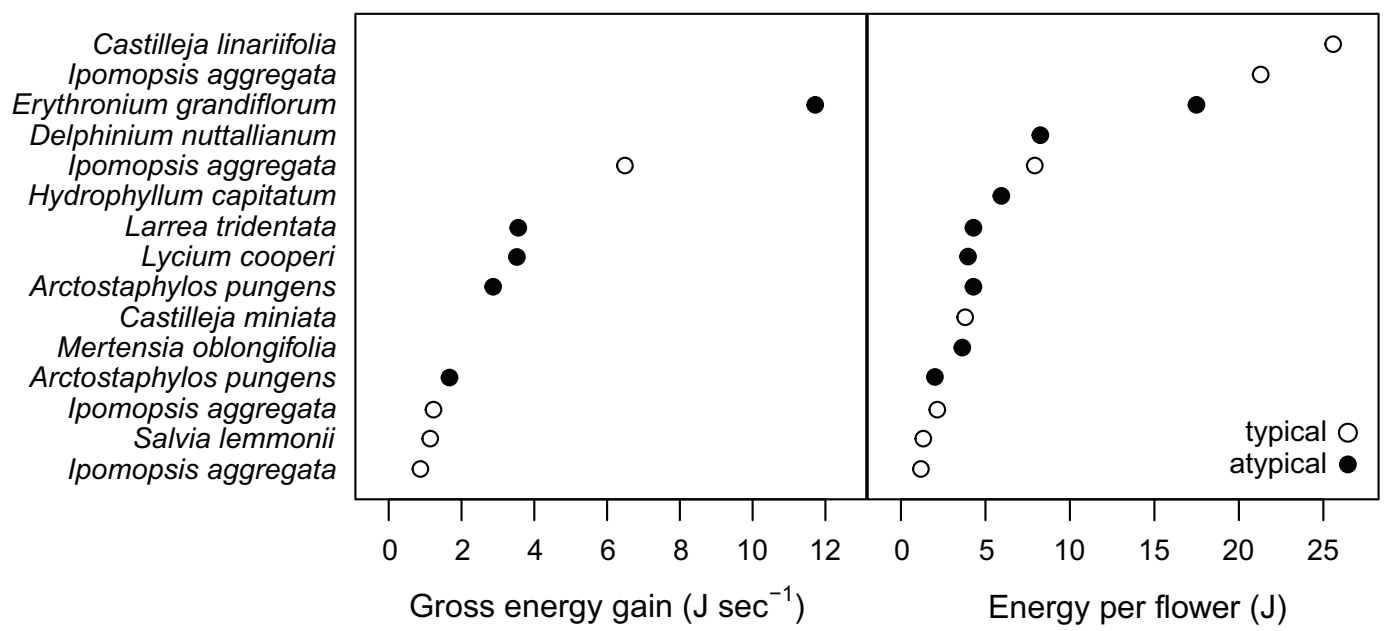

Figure 3: Comparisons of the energetic profitability of hummingbird foraging at the typical and atypical flowers shown in figure 1. Profitability is estimated in two ways: as gross rate of energy gain (left) and as mean energetic value of the sugar found in flowers (right). The samples for which we have estimates of mean energetic value include those for which we have estimates of gross gain but also include several for which we lack estimates of hummingbird foraging speed. See table 1 for numerical values of the profitability estimates depicted here. Species included more than once represent samples from different times or locations.

in 1986 (table 1; fig. 1A, 1D). Because those samples lack matched foraging speed measurements, they provide a less exact measure of profit - the average energetic reward $(J)$ per flower. But there is considerable overlap overall in the range of energy contents of typical and atypical flowers (figs. 1, 3; table 1). This finding calls into question the hypothesis of Heinrich and Raven (1972) and more generally the tacit assumption that flowers will evolve features that are optimal for their pollinators rather than those that are optimal for the plants themselves (see Pyke and Waser 2017).

\section{What Have We Learned from These Observations?}

Our observations are far from unique: hummingbird foraging on Arctostaphylos species was reported by Bent (1940) and Grant and Grant (1967); on Lycium species by Bent (1940) and Grant and Grant (1968); on Ribes species (Grossulariaceae) by Bent (1940), Bené (1946), and Grant and Grant (1968); on Mertensia species and Hydrophyllum capitatum by Waser (1983); and on Hyptis emoryi (Lamiaceae) by Bent (1940). There are many other examples (e.g., fig. A1), but what we add here, combining basic tools for measuring nectar with knowledge of hummingbird physiology, is the conclusion that hummingbirds in the western United States are making a profit — not a "mistake" — when they forage systematically at such atypical flowers.

In the absence of landscape-scale knowledge of identities and densities of flowers and their visitors as well as of nectar production and use, we cannot absolutely conclude that atypical flowers did support overnight residency of the hummingbirds we observed (although at several sites it is difficult to envision other suitable options the birds had within reasonable flight range), nor can we estimate carrying capacity for hummingbirds. At the same time, our results do indicate that rewards from atypical flowers can provide an immediate energetic profit that, if maintained, should support residency and that the profit can resemble that obtained from typical hummingbird flowers.

\section{Implications for Hummingbirds}

Atypical flowers may provide significant support not only for residency but also for long-distance migration (Calder 2004) and regional movements (sensu Levey and Stiles 1992). Estimates of floral resources in hummingbird habitats and movement corridors - critical for hummingbird conservationwould best include a consideration of all potential resources, not just typical hummingbird flowers.

\section{Implications for Plants}

Do atypical flowers benefit from the attention of hummingbirds? Hummingbirds contribute to pollination if some part of their bill makes contact with stigmas and anthers, which can occur even when flowers are small and shallow ("billtip" pollination; Grant and Grant 1968). Few data exist to indicate how often atypical flowers are pollinated by hummingbirds, but we do know that hummingbirds can carry their pollen. For example, in the summer of 2016 Broad-tailed Hummingbirds at the RMBL carried pollen from small-flowered gooseberries (Ribes spp.), bluebells (Mertensia spp.), and even 
willows (Salix spp., Salicaceae; I. Chen, personal communication).

\section{Concluding Remarks}

By attending to our natural history observations over many decades, we have learned that hummingbirds can make a profit from many types of flowers and that atypical flowers can provide as much energy as typical hummingbird flowers. If we focus only on the flowers we expect hummingbirds to visit, we get an incomplete picture of the resources available to them and an incomplete understanding of their behavior, movements, life cycles, and demography. The converse is also true: if we focus only on animals that we expect will pollinate a flower, we may obtain an incomplete understanding of their pollination (see also Mayfield et al. 2001; Waser et al. 2011; Cane and Dunne 2014).

We agree with Tetlock and Garner $(2015$, p. 191) that "beliefs are hypotheses to be tested, not treasures to be protected." Our understanding of the natural world is enriched if we attend to all available data, whether obtained by formal experiment or casual observation - especially data that surprise us and challenge our expectations.

\section{Acknowledgments}

This article is dedicated to the memory of William A. Calder III, "Dr. Hummingbird," who introduced N.M.W. and M.V.P. to hummingbirds and to the interface among physiology, behavior, and ecology. Thanks to Irina Chen for records of pollen carried by hummingbirds at the Rocky Mountain Biological Laboratory; to Audrey Boag, David Inouye, Neal Kramer, Gary Monroe, Jane Ogilvie, Keir Morse, and Bart Jones for photographs; and to Audrey Boag, Brooke Gebow, Amy Iler, and Linda Kennedy for comments on the manuscript. Comments from Mark McPeek and two anonymous reviewers greatly improved the manuscript. Our measurements of hummingbirds are from individuals captured under federal banding permit 20527 and state permits granted to N.M.W. 


\section{APPENDIX}

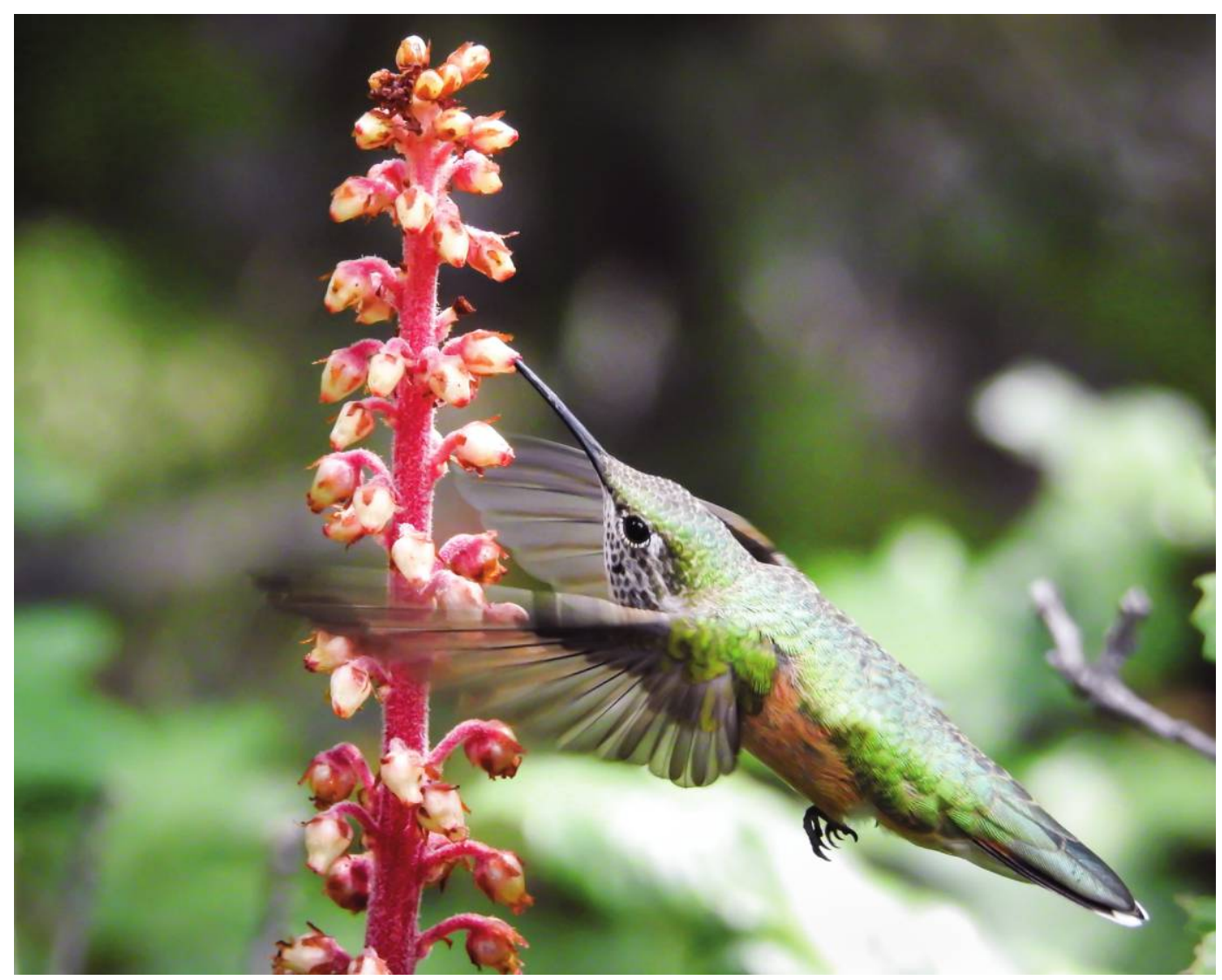

Figure A1: Fledgling Broad-tailed Hummingbird (Selasphorus platycercus) feeding systematically from the tiny flowers of pinedrops (Pterospora andromedea). This parasitic plant is in the same family (Ericaceae) as manzanita (Arctostaphylos spp.; see the main text for details), and the flowers are similar in size and shape. Photograph courtesy of Audrey Boag, Indian Hills, Colorado.

\section{Literature Cited}

Austin, D. F. 1975. Bird flowers in the eastern United States. Florida Scientist 38:1-12.

Bené, F. 1946. The feeding and related behavior of hummingbirds. Memoirs of the Boston Society of Natural History 9:403-478.

Bent, A. C. 1940. Life histories of North American cuckoos, goatsuckers, hummingbirds, and their allies. Smithsonian, Washington, DC.

Bolten, A. B., P. Feinsinger, H. G. Baker, and I. Baker. 1979. On the calculation of sugar concentration in flower nectar. Oecologia 41:301304.

Brice, A. T. 1992. The essentiality of nectar and arthropods in the diet of the Anna's Hummingbird (Calypte anna). Comparative Biochemistry and Physiology A 101:151-155.

Calder, W. A. 1971. Temperature relationships and nesting of the Calliope Hummingbird. Condor 73:314-321.

. 2004. Rufous and Broad-tailed Hummingbirds: pollination, migration, and population biology. Pages 59-79 in G. P. Nabhan, ed. Conserving migratory pollinators and nectar corridors in western North America. University of Arizona Press, Tucson.
Calder, W. A., and J. Booser. 1973. Hypothermia of Broad-tailed Hummingbirds during incubation in nature with ecological correlations. Science 180:751-753.

Calder, W. A., L. L. Calder, and T. D. Fraizer. 1990. The hummingbird's restraint: a natural model for weight control. Experientia 46 : 999-1002.

Cane, J. H., and R. Dunne. 2014. Generalist bees pollinate red-flowered Penstemon eatonii: duality in the hummingbird pollination syndrome. American Midland Naturalist 171:365-370.

Dakin, R., P. S. Segre, A. D. Straw, and D. L. Altshuler. 2018. Morphology, muscle capacity, skill, and maneuvering ability in hummingbirds. Science 359:653-657.

Frey-Wyssling, A., M. Zimmerman, and A. Maurizio. 1954. Über den enzymatischen Zuckerumbau in Nektarien. Experientia 10:490492.

Gass, C. L., and K. P. Lertzman. 1980. Capricious mountain weather: a driving variable in hummingbird territorial dynamics. Canadian Journal of Zoology 58:1964-1968.

Goldsmith, K. M., and T. H. Goldsmith. 1982. Sense of smell in the Black-chinned Hummingbird. Condor 84:237-238. 
Goldsmith, T. H., and K. M. Goldsmith. 1979. Discrimination of colors by the black-chinned hummingbird (Archilochus alexandri). of Comparative Physiology A 130:209-220.

Grant, K. A., and V. Grant. 1968. Hummingbirds and their flowers. Columbia University Press, New York.

Grant, V., and K. A. Grant. 1967. Records of hummingbird pollination in the western American flora. II. Additional California records. Aliso 6:103-105.

Grant, V., and E. J. Temeles. 1992. Foraging ability of Rufous Hummingbirds on hummingbird flowers and hawkmoth flowers. Proceedings of the National Academy of Sciences of the USA 89:94009404.

Heinrich, B., and P. H. Raven. 1972. Energetics and pollination ecology. Science 176:597-602.

Hixon, M. A., F. L. Carpenter, and D. C. Paton. 1983. Territory area, flower density and time budgeting in hummingbirds: an experimental and theoretical analysis. American Naturalist 122:366-391.

Johnsgard, P. A. 1983. The hummingbirds of North America. Smithsonian, Washington, DC.

Karasov, W. H., D. Phan, J. M. Diamond, and F. L. Carpenter. 1986. Food passage and intestinal nutrient absorption in hummingbirds. Auk 103:453-464.

Knudsen, J. T., L. Tollsten, I. Groth, G. Bergstrom, and R. A. Raguso. 2004. Trends in floral scent chemistry in pollination syndromes: floral scent composition in hummingbird-pollinated taxa. Botanical Journal of the Linnean Society 146:191-199.

Lasiewski, R. C. 1963. Oxygen consumption of torpid, resting, active, and flying hummingbirds. Physiological Zoology 36:122-140.

Levey, D. J., and F. G. Stiles. 1992. Evolutionary precursors of longdistance migration: resource availability and movement patterns in Neotropical landbirds. American Naturalist 140:447-476.

Lunau, K., S. Papiorek, T. Eltz, and M. Sazima. 2011. Avoidance of achromatic colours by bees provides a private niche for hummingbirds. Journal of Experimental Biology 214:1607-1612.

Martínez del Rio, C., H. G. Baker, and I. Baker. 1992. Ecological and evolutionary implications of digestive processes: bird preferences and the sugar constituents of floral nectar and fruit pulp. Experientia 48:544-551.

Mayfield, M. M., N. M. Waser, and M. V. Price. 2001. Exploring the "most effective pollinator principle" with complex flowers: bumblebees and Ipomopsis aggregata. Annals of Botany 88:591-596.

Powers, D. R. 1987. Effects of variation in food quality on the breeding territoriality of the male Anna's Hummingbird. Condor 89:103111.

Powers, D. R., and T. M. Conley. 1994. Field metabolic rate and food consumption of two sympatric hummingbird species in southeastern Arizona. Condor 96:141-150.
Powers, D. R., and K. A. Nagy. 1988. Field metabolic rate and food consumption by free-living Anna's Hummingbirds (Calypte anna). Physiological Zoology 61:500-506.

Pyke, G. H. 1984. Optimal foraging theory: a critical review. Annual Review of Ecology and Systematics 15:523-575.

Pyke, G. H., and N. M. Waser. 2017. Comment on "Cognition-Mediated Evolution of Low-Quality Floral Nectars.” Science 358:eaao1962. doi:10.1126/science.aao1962.

Richardson, L. L., and J. L. Bronstein. 2012. Reproductive biology of pointleaf manzanita (Arctostaphylos pungens) and the pollinatornectar robber spectrum. Journal of Pollination Ecology 9:115-123.

Rico-Guevara A., T.-H. Fan, and M. A. Rubega. 2015. Hummingbird tongues are elastic micropumps. Proceedings of the Roval Society B 282:20151014.

Roberts, W. M. 1996. Hummingbirds' nectar concentration preferences at low volume: the importance of time scale. Animal Behaviour 52:361-370.

Scheithauer, W. 1967. Hummingbirds. Cromwell, New York.

Skutch, A. F., and A. B. Singer. 1973. The life of the hummingbird. Crown, New York.

Stiles, F. G. 1976. Taste preference, color preference, and flower choice in hummingbirds. Condor 78:10-26.

Tegmark, M. 2014. Our mathematical universe: my quest for the ultimate nature of reality. A. A. Knopf, New York.

Tetlock, P. E., and D. Gardner. 2015. Superforecasting: the art and science of prediction. Broadway, New York.

Waser, N. M. 1976. Food supply and nest timing of Broad-tailed Hummingbirds in the Rocky Mountains. Condor 78:133-135.

. 1983. The adaptive nature of floral traits: ideas and evidence. Pages 241-285 in L. A. Real, ed. Pollination biology. Academic Press, New York.

Waser, N. M., P. J. CaraDonna, and M. V. Price. 2018. Data from: Atypical flowers can be as profitable as typical hummingbird flowers. American Naturalist, Dryad Digital Repository, http://dx.doi.org /10.5061/dryad.cd4h7f1.

Waser, N. M., J. Ollerton, and A. Erhardt. 2011. Typology in pollination biology: lessons from an historical critique. Journal of Pollination Ecology 3:1-7.

Weathers, W. W., W. A. Buttemer, A. M. Hayworth, and K. A. Nagy. 1984. An evaluation of time-budget estimates of daily energy expenditure in birds. Auk 101:459-472.

Wolf, L. L., and F. R. Hainsworth. 1971. Time and energy budgets of territorial hummingbirds. Ecology 52:980-988.

Wolf, L. L., F. R. Hainsworth, and F. G. Stiles. 1972. Energetics of foraging: rate and efficiency of nectar extraction by hummingbirds. Science 176:1351-1352.

Natural History Editor: Mark A. McPeek 